\title{
A Quinoline Antibiotic from Rhodococcus erythropolis JCM 6824
}

Wataru Kitagawa, Tomohiro Tamura

Received: August 26, 2008 / Accepted: October 25, 2008

(C) Japan Antibiotics Research Association

\begin{abstract}
A new quinoline antibiotic, aurachin RE, was isolated and identified from a culture broth of Rhodococcus erythropolis JCM 6824. The aurachin RE structure was determined based on NMR and mass spectrometric analysis. The structure is similar to that of aurachin $\mathrm{C}$ antibiotics that have been identified from Stigmatella aurantiaca. Compared to aurachin $\mathrm{C}$, however, aurachin $\mathrm{RE}$ exhibits a wide and strong antimicrobial spectrum against both high- and low-GC Gram-positive bacteria.
\end{abstract}

Keywords Actinobacteria, antibiotic, aurachin, quinoline, Rhodococcus

Large numbers of antibiotics have been isolated from the Actinobacteria, including those from the genera, Streptomyces and Nocardia. Recently, we have reported the genus Rhodococcus is also a prolific antibiotic producer [1]. At least, five species and 18 strains of Rhodococcus have been demonstrated to exhibit anti-microbial activity. $R$. erythropolis, in particular, includes three groups of strains that produce respective antibiotics [1]. One of the antibiotic-producing strains, $R$. erythropolis JCM 6824, and also the partially purified antibiotic isolated from this strain, exhibits strong antibiotic against a broad range of Gram-positive bacteria. Further investigations on the metabolites of this strain have resulted in the isolation of a new quinoline antibiotic compound designated aurachin
RE [1a; IUPAC name: 1-hydroxy-2-methyl-3-(3,7,11trimethyldodeca-9-hydroxy-2,6,10-trienyl)quinolin-4-one]. In this paper, we report on the isolation, structure elucidation, and biological properties of this compound.

$R$. erythropolis JCM 6824 was cultured in W-minimal medium [2] supplemented with succinate $(0.2 \%, \mathrm{w} / \mathrm{v})$, sucrose $(0.2 \%, \mathrm{w} / \mathrm{v})$, and casamino acids $(0.2 \%, \mathrm{w} / \mathrm{v})$. Stock seed cultures $\left(10^{6} \mathrm{cfu} / \mathrm{ml}\right)$ were maintained at $-80^{\circ} \mathrm{C}$ in $10 \%$ glycerol. A $600-\mu 1$ aliquot of stock seed was transferred into each of six 2-liters baffled Erlenmeyer flasks containing $600 \mathrm{ml}$ of the culture medium. The fermentation was carried out on a rotary shaker at $28^{\circ} \mathrm{C}$ for 28 hours with agitation of $120 \mathrm{rpm}$.

The fermentation broth (3.6 liters) was centrifuged and any residual cells in the supernatant were removed by membrane filtration $(0.2-\mu \mathrm{m}$ pore size). The filtered supernatant was applied to a $\mathrm{C} 18$ cartridge column (SepPak ${ }^{\circledR}$ Vac 35 cc; Waters, Milford, MA), and the column was sequentially washed with $100 \mathrm{ml}$ of $20 \% \mathrm{EtOH}$ and $30 \mathrm{ml}$ of $50 \% \mathrm{EtOH}$. The sample was eluted with $20 \mathrm{ml}$ of $\mathrm{EtOH}$ and then evaporated to dryness. The residue was

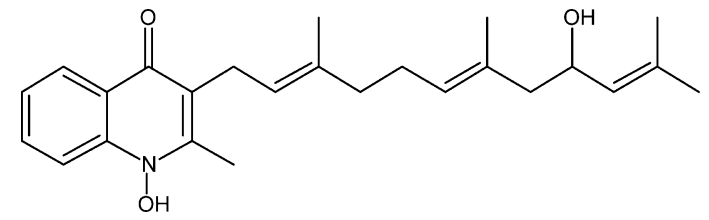

Aurachin RE (1a) and aurachin C (1) $\mathbf{b}$ : H instead of $\left.9^{\prime}-\mathrm{OH}\right)$
W. Kitagawa (Corresponding author), T. Tamura: Research Institute of Genome-based Biofactory, National Institute of Advanced Industrial Science and Technology (AIST), 2-17-2-1, Tsukisamu-Higashi, Toyohira-ku, Sapporo 062-8517, Japan, Email: w-kitagawa@aist.go.jp
T. Tamura: Laboratory of Molecular Environmental Microbiology, Graduate School of Agriculture, Hokkaido University, Kita-9, Nishi-9, Kita-ku, Sapporo 060-8589, Japan 
dissolved in $1 \mathrm{ml}$ of $\mathrm{EtOH}$, and this solution was used for purification. The sample was subjected to reversed-phase HPLC [column: TSKgel ODS-80Ts, $4.6 \mathrm{~mm} \mathrm{I.D.} \times 15 \mathrm{~cm}$ (TOSOH, Tokyo, Japan); mobile phase: $65 \sim 75 \% \mathrm{MeOH}$ ( $0 \sim 8$ minutes) and $90 \% \mathrm{MeOH}$ ( $8 \sim 12$ minutes); flow rate: $1.0 \mathrm{ml} /$ minute; monitor wavelength: $220 \sim 600 \mathrm{~nm}$ ] [1]. A single peak that retained antibiotic activity and eluted at a retention time of 10.6 minutes, was reproducibly collected. This process yielded $0.5 \mathrm{mg}$ of pure aurachin RE (1a) from the original 3.6-liters culture.

The appearance of the purified compound 1a is graybrown, and it is soluble in $\mathrm{EtOH}, \mathrm{MeOH}, \mathrm{CH}_{3} \mathrm{CN}$, EtOAc, and DMSO, and moderately soluble in water. The molecular formula of 1a was determined to be $\mathrm{C}_{25} \mathrm{H}_{33} \mathrm{NO}_{3}$ $(\mathrm{MW}=395)$, on the basis of positive ESI/MS data $(\mathrm{m} / \mathrm{z}$ found, $396.2527[\mathrm{M}+\mathrm{H}]^{+}$; calcd, 396.2533) obtained using a QSTAR XL mass spectrometer (Applied Biosystems, Foster City, CA). The structure of 1a was elucidated by

Table $1{ }^{1} \mathrm{H}$ - and ${ }^{13} \mathrm{C}-\mathrm{NMR}$ spectral data of $\mathbf{1 a}$ in DMSO- $d_{6}$

\begin{tabular}{|c|c|c|}
\hline Position & $\delta_{\mathrm{C}}$ & $\delta_{\mathrm{H}}$ \\
\hline 2 & 147.8 & \\
\hline 3 & 117.9 & \\
\hline 4 & 173.1 & \\
\hline $4 a$ & 123.6 & \\
\hline 5 & 125.5 & $8.11(1 \mathrm{H}, \mathrm{dd}, J=1.4,6.9 \mathrm{~Hz})$ \\
\hline 6 & 122.9 & $7.29(1 \mathrm{H}, \mathrm{t}, J=7.3 \mathrm{~Hz})$ \\
\hline 7 & 131.6 & $7.64(1 \mathrm{H}, \mathrm{dd}, J=1.4,6.9 \mathrm{~Hz})$ \\
\hline 8 & 114.7 & $7.77(1 \mathrm{H}, \mathrm{d}, J=8.2 \mathrm{~Hz})$ \\
\hline $8 a$ & 139.7 & \\
\hline 9 & 14.7 & $2.39(3 \mathrm{H}, \mathrm{s})$ \\
\hline $1^{\prime}$ & 24.2 & $3.29(2 \mathrm{H}, \mathrm{d}, J=6.8 \mathrm{~Hz})$ \\
\hline $2^{\prime}$ & 123.1 & $4.98(1 \mathrm{H}, \mathrm{m})$ \\
\hline $3^{\prime}$ & 134.3 & \\
\hline $4^{\prime}$ & 39.3 & $1.90(2 \mathrm{H}, \mathrm{m})$ \\
\hline $5^{\prime}$ & 26.4 & $1.99(2 \mathrm{H}, \mathrm{m})$ \\
\hline $6^{\prime}$ & 126.1 & $5.02(1 \mathrm{H}, \mathrm{m})$ \\
\hline $7^{\prime}$ & 132.1 & \\
\hline \multirow[t]{2}{*}{$8^{\prime}$} & 48.3 & $1.88(1 \mathrm{H}, \mathrm{m})$ \\
\hline & & $2.06(1 \mathrm{H}, \mathrm{m})$ \\
\hline $9^{\prime}$ & 66.1 & $4.21(1 \mathrm{H}, \mathrm{q}, J=7.3 \mathrm{~Hz})$ \\
\hline $10^{\prime}$ & 130.0 & $5.00(1 \mathrm{H}, \mathrm{m})$ \\
\hline $11^{\prime}$ & 131.1 & \\
\hline $12^{\prime}$ & 25.6 & $1.59(3 \mathrm{H}, \mathrm{s})$ \\
\hline $13^{\prime}$ & 16.2 & $1.72(3 \mathrm{H}, \mathrm{s})$ \\
\hline $14^{\prime}$ & 16.6 & $1.53(3 \mathrm{H}, \mathrm{s})$ \\
\hline $15^{\prime}$ & 18.1 & $1.52(3 \mathrm{H}, \mathrm{s})$ \\
\hline
\end{tabular}

${ }^{1} \mathrm{H}$ - and ${ }^{13} \mathrm{C}-\mathrm{NMR}$ were measured at $400 \mathrm{MHz}$ and $100 \mathrm{MHz}$, respectively. Chemical shifts are shown in $\delta$ values relative to DMSO- $d_{6}$ at $\delta=2.49$ for ${ }^{1} \mathrm{H}$-NMR and at $\delta=39.7$ for ${ }^{13} \mathrm{C}$-NMR values. extensive NMR analysis; the chemical shifts in the ${ }^{1} \mathrm{H}$ - and ${ }^{13} \mathrm{C}$-NMR of 1a are shown in Table 1 . The ${ }^{1} \mathrm{H}-\mathrm{NMR}$ spectrum and HSQC analysis indicated the presence of 15 methyl protons, eight methylene protons, and eight methine protons, the latter of which included three olefinic protons, and four aromatic protons. The ${ }^{13} \mathrm{C}-\mathrm{NMR}$ spectrum indicated the presence of 25 carbon atoms, which were assigned to five methyls, four methylenes, eight methines, and eight quaternary carbons using DEPT spectrum. DQF COSY and HMBC experiments confirmed the partial structures of 1a. As a result, the whole structure of $1 \mathrm{a}$ was determined as shown in Fig. 1.

The structure of compound $\mathbf{1 a}$ is highly similar to that of the antibiotic aurachin $\mathrm{C}(\mathbf{1 b})$, which was isolated from the Gram-negative myxobacterium, Stigmatella aurantiaca $\mathrm{Sg}$ a15 [3]. The sole difference between the two compounds is the presence of a hydroxyl group on the hydrocarbon chain

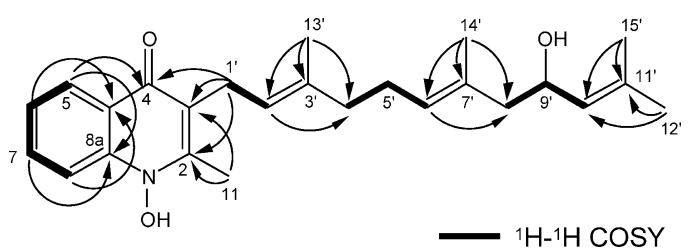

Fig. 1 COSY and HMBC correlations of 1a.

Table 2 Antimicrobial spectrum of $\mathbf{1 a}$

\begin{tabular}{|c|c|}
\hline Test organism & $\begin{array}{c}\text { Inhibition zone } \\
(\mathrm{mm})^{\mathrm{a}}\end{array}$ \\
\hline Sphingomonas paucimobilis IAM $12576^{\top}$ & trace \\
\hline Sinorhizobium meliloti IAM $12611^{\top}$ & 24 \\
\hline Paracoccus aminovorans IAM $14244^{\top}$ & - \\
\hline Comamonas testosteroni IAM $12419^{\top}$ & - \\
\hline Ralstonia eutropha IAM 12368 & - \\
\hline Pseudomonas putida IAM $1236^{\top}$ & - \\
\hline Escherichia coli $\mathrm{K}-12^{\mathrm{b}}$ & - \\
\hline Acinetobacter calcoaceticus IAM $12087^{\top}$ & - \\
\hline Deinococcus grandis IAM $13005^{\top}$ & 35 \\
\hline Bacillus subtilis IAM $12118^{\top}$ & 20 \\
\hline Paenibacillus polymyxa IAM 13419 & 38 (turbid) \\
\hline Arthrobacter atrocyaneus IAM $12339^{\top}$ & 38 \\
\hline Corynebacterium glutamicum IAM $12435^{\top}$ & 29 \\
\hline Nocardia pseudosporangifera IAM $501^{\top}$ & 35 \\
\hline Streptomyces griseus IAM $12311^{\top}$ & 30 \\
\hline Rhodococcus erythropolis IAM $12122^{\top}$ & 28 \\
\hline Saccharomyces cerevisiae W303 ${ }^{\mathrm{b}}$ & - \\
\hline
\end{tabular}

\footnotetext{
a $10 \mu \mathrm{g}$ of antibiotic were applied on paper disks (6 $\mathrm{mm}$ diameter).

${ }^{\mathrm{b}}$ Laboratory stock.

${ }^{\top}$ Type strain.
} 
(position $\mathrm{C}-9^{\prime}<$ substituted) in compound 1a. The antimicrobial spectrum of compound 1a was tested by an agar diffusion assay using $10 \mu \mathrm{g}$ of compound (Table 2). Compound 1a exhibit wide and strong antibiotic activity against Gram-positive bacteria. Compound 1b has also been reported to exhibited antibiotic activity against Grampositive bacteria; however, in comparison, compound 1a appeared to possess considerably stronger activity. For example, $10 \mu \mathrm{g}$ of 1a produced large growth inhibition zones against Nocardia sp. and Streptomyces sp. (Table 2), whereas $40 \mu \mathrm{g}$ of $\mathbf{1 b}$ exhibited only trace antibiotic activity against these species according to the literature [3]. In addition, compound 1a exhibited activity against the Gramnegative bacteria, Sinorhizobium sp. and Deinococcus sp. Though several aurachin analogs have previously been isolated and synthesized [3, 4], no hydroxylated analogs (on the hydrocarbon chain) have been reported and tested. The hydroxyl group might increase the solubility of the compound in the aqueous phase and may also increase its ability to permeate bacterial cell walls. Thus, introducing a hydroxyl group might be a key factor in improving the activities of these compounds. The MIC values of compound 1a against various organisms were also examined and the determined values are listed in Table 3. This study again demonstrated that this antibiotic is highly active against Gram-positive bacteria, particularly against the Actinobacteria. Compound $\mathbf{1 b}$ has been reported to exhibited MIC values of $0.2 \mu \mathrm{g} / \mathrm{ml}$ and $0.8 \mu \mathrm{g} / \mathrm{ml}$ against Arthrobacter sp., and Corynebacterium sp., respectively [3]. In contrast, compound 1a exhibited a minimum MIC value of $0.01 \mu \mathrm{g} / \mathrm{ml}$ against Arthrobacter sp., Corynebacterium sp., and Nocardia sp.

Recently, biosynthetic genes for aurachins $(a u a A \sim E)$ have been isolated and published [5]. Preliminary PCR screening for these genes in $R$. erythropolis JCM 6824 gave

Table 3 Minimal inhibitory concentrations of $\mathbf{1 a}$

\begin{tabular}{lc}
\multicolumn{1}{c}{ Test organism } & MIC $(\mu \mathrm{g} / \mathrm{ml})$ \\
\hline Sinorhizobium meliloti IAM 12611 $^{\top}$ & 0.4 \\
Escherichia coli K-12 $^{c}$ & 50 \\
Deinococcus grandis IAM 13005 & \\
Bacillus subtilis IAM 12118 $^{\top}$ & 0.2 \\
Arthrobacter atrocyaneus IAM 12339 $^{\top}$ & 3.1 \\
Corynebacterium glutamicum IAM 12435 $^{\top}$ & 0.01 \\
Nocardia pseudosporangifera IAM 501 $^{\top}$ & 0.01 \\
Streptomyces griseus IAM 12311 $^{\top}$ & 0.01 \\
Rhodococcus erythropolis IAM 12122 $^{\top}$ & 0.1 \\
Saccharomyces cerevisiae W303 & 0.1 \\
\hline
\end{tabular}

no amplified products (data not shown). These results indicated that this Rhodococcus strain does not contain aua-type biosynthetic genes or biosynthetic genes similar to those that have been isolated from Stigmatella. Although to date, two antibiotics have been isolated from the genus Rhodococcus [6 8], the biosynthetic genes for these compounds have not been identified.

Acknowledgment We gratefully acknowledge the devoted and expert technical assistance of Miyako Hata in this investigation.

\section{References}

1. Kitagawa W, Tamura T. Three types of antibiotics produced from Rhodococcus erythropolis strains. Microbes Environ 23: 167-171 (2008)

2. Kitagawa W, Takami S, Miyauchi K, Masai E, Kamagata Y, Tiedje JM, Fukuda M. Novel 2,4-dichlorophenoxyacetic acid degradation genes from oligotrophic Bradyrhizobium sp. strain HW13 isolated from a pristine environment. J Bacteriol 184: 509-518 (2002)

3. Kunze B, Höfle G, Reichenbach H. The aurachins, new quinoline antibiotics from myxobacteria: production, physico-chemical and biological properties. J Antibiot 40: 258-265 (1987)

4. Miyoshi H, Takegami K, Sakamoto K, Mogi T, Iwamura H. Characterization of the ubiquinol oxidation sites in cytochromes bo and $b d$ from Escherichia coli using aurachin C analogues. J Biochem 125: 138-142 (1999)

5. Sandmann A, Dickschat J, Jenke-Kodama H, Kunze B, Dittmann E, Müller R. A type II polyketide synthase from the gram-negative bacterium Stigmatella aurantiaca is involved in aurachin alkaloid biosynthesis. Angew Chem Int Ed Engl 46: 2712-2716 (2007)

6. Iwatsuki M, Uchida R, Takakusagi Y, Matsumoto A, Jiang CL, Takahashi Y, Arai M, Kobayashi S, Matsumoto M, Inokoshi J, Tomoda H, Ōmura S. Lariatins, novel antimycobacterial peptides with a lasso structure, produced by Rhodococcus jostii K01-B0171. J Antibiot 60: 357-363 (2007)

7. Iwatsuki M, Tomoda H, Uchida R, Gouda H, Hirono S, Ōmura S. Lariatins, antimycobacterial peptides produced by Rhodococcus sp. K01-B0171, have a lasso structure. J Am Chem Soc 128: 7486-7491 (2006)

8. Chiba H, Agematu H, Kaneto R, Terasawa T, Sakai K, Dobashi K, Yoshioka T. Rhodopeptins (Mer-N1033), novel cyclic tetrapeptides with antifungal activity from Rhodococcus sp. I. Taxonomy, fermentation, isolation, physico-chemical properties and biological activities. J Antibiot 52: 695-699 (1999) 